\title{
REAPROVEITAMENTO DA AREIA DE FORMIGUEIRO EM FERTILIZANTE NA HORTA ESCOLAR COMO CONTRIBUIÇÃO AO ENSINO DE GEOGRAFIA
}

Cristiane e Castro Feitosa Melo ${ }^{1}$

Resumo: Essa pesquisa tem como principal objetivo analisar a contribuição da experiência do reaproveitamento da areia de formigueiro em fertilizante na horta da escola pública, como contribuição ao ensino de geografia dos alunos do Ensino Fundamental. Trata-se de uma pesquisa qualitativa do tipo estudo de caso etnográfico. O trabalho está estruturado em duas partes. Na primeira Conhecimento da ecologia para o exercício da cidadania - apresenta uma retrospectiva da educação ambiental na política global e escolar. Na segunda parte A experiência do reaproveitamento da areia de formigueiro em fertilizante natural na horta escolar - registra a experiência pedagógica desenvolvida em uma escola pública do município de Fortaleza. Por último, apresenta as considerações finais, discutindo a necessidade de uma tomada de consciência em relação à geografia em conjunto com a educação ambiental para fortalecer as ações humanas.

Palavras-chave: Areia de Formigueiro. Fertilizante Natural. Horta Escolar. Geografia.

\section{REUSE ANTHILL SAND IN FERTILIZER IN THE SCHOOL VEGETABLE GARDEN AS CONTRIBUTION TO THE TEACHING OF GEOGRAPHY}

Abstract: This research aims primarily to analyze the contribution of the experience of reuse anthill sand in fertilizer in the public school vegetable garden, as contribution to geography learning by Basic Education students. This is a qualitative research of ethnographic case study type. The study is structured into two parts. The first Knowledge of ecology for the exercise of citizenship - provides a retrospective of environmental education in global politics and in schools. The second part - The experience of reuse of anthill sand in fertilizer in the school vegetable garden records the educational experiment developed in a public school in the Fortaleza city. Finally, it presents the final considerations and discusses the need of awareness in relation to geography and also with environmental education to strengthen for human actions.

Keywords: Anthill Sand. Natural Fertilizer. School Vegetable Garden. Geography.

\section{REAPROVEITAMIENTO DE LA ARENA DE HORMIGÓN EN FERTILIZANTE EN LA HORTA ESCOLAR COMO CONTRIBUCIÓN A LA ENSEÑANZA DE GEOGRAFÍA}

Resumen: Esta investigación tiene como principal objetivo analizar la contribución de la experiencia del reaprovechamiento de la arena de hormiguero en fertilizante en la huerta de la escuela pública, como contribución a la enseñanza de geografía de los alumnos de la Enseñanza Fundamental. Se trata de una investigación cualitativa del tipo estudio de caso etnográfico. El trabajo está estructurado en dos partes. En la primera - Ecología y Concientización: caminos para el ejercicio de la ciudadanía presenta una retrospectiva del ambientalismo en la política global y escolar. En la segunda parte - La experiencia del reaprovechamiento de la arena de hormiguero en

\footnotetext{
${ }^{1}$ Universidade Estadual do Ceará, Programa de Pós-Graduação em Geografia, Fortaleza, Brasil, cristianefeitosa@hotmail.com, https://orcid.org/0000-0003-3426-1148
} 
fertilizante en la huerta de la escuela - registra la experiencia pedagógica desarrollada en una escuela pública del municipio de Fortaleza. Por último, presenta las consideraciones finales, discutiendo la necesidad de una toma de conciencia en relación a la geografía en conjunto con la educación ambiental para fortalecer las acciones humanas.

Palabras clave: Arena de hormiguero. Fertilizante Natural. Horta Escolar. Geografía.

\section{Introdução}

Essa pesquisa aborda o ensino de geografia no Ensino Fundamental, focalizando o reaproveitamento da areia de formigueiro em fertilizante natural na horta escolar como forma de recuperação do solo e como contribuição à educação ambiental. Desse modo, toma como referência uma experiência pedagógica realizada no $8^{\circ}$ e 9ำ ano em uma escola pública no município de Fortaleza.

A preocupação central deste trabalho pode ser assim resumida: qual a colaboração da experiência do reaproveitamento da areia de formigueiro em fertilizante na horta escolar como contribuição ao ensino de geografia dos alunos do ensino fundamental (do 8. e 9. ano)? Indaga até que ponto uma experiência teórico-prática pode contribuir para a formação de cidadãos que conscientemente refletem sobre os seus direitos e deveres e dos demais grupos que compõem a sociedade para com o meio ambiente, na construção de um espaço geográfico saudável, constituindo, portanto, num veículo para a modificação da prática de determinadas ações que agridem a natureza.

O reaproveitamento da areia de formigueiro em fertilizante natural é o tema discutido e analisado em duas partes: A primeira parte - Conhecimento da Ecologia para o Exercício da Cidadania - revisa a história do movimento mundial de conscientização ecológica na política global, mostrando o ambiente escolar, e a difícil relação entre ecologia e economia, no intuito de compreender a sociedade das formigas cortadeiras na produção da areia de formigueiro, que serve como fertilizante natural na horta escolar. Também mostra A Pesquisa do Tipo Etnográfico em Educação, onde discorre da pesquisa qualitativa como opção metodológica, realizando uma discussão empírica.

$\mathrm{Na}$ segunda parte - $A$ experiência do reaproveitamento da areia de formigueiro em fertilizante natural na horta escolar - faz-se uma descrição da experiência da confecção e uso da areia de formigueiro em fertilizante natural junto aos alunos do 8.ำ ao 9.ำ ano e as possibilidades de contribuição, da mesma, como auxílio ao ensino de geografia dos alunos do Ensino Fundamental. 
Por fim, cabe registrar que esse assunto não se esgota aqui. Ao contrário, trata-se de um ponto de partida, o qual deve ser aprofundado por outros interessados em desvendar a contribuição do reaproveitamento da areia de formigueiro em fertilizante na horta escolar como componente social responsável pelo aumento da formação e das ações humanas, o que vem a facilitar a tomada de consciência em relação à responsabilidade no Ensino Fundamental.

\title{
Conhecimento da ecologia para o exercício da cidadania
}

Ecologia, de acordo com Melo (2012, p. 38; 2019, p. 03), "é o estudo das relações entre seres vivos e o meio onde vivem bem como suas recíprocas influências". Para o autor citado,

\begin{abstract}
A crise ecológica global se origina na radicalidade alcançada nos tempos modernos pela dualidade Terra - mundo, já que esta, por ser inerente ao princípio ativo da civilização, é também inevitável. Por esta razão, a ecologia, o ambientalismo e o ethos ecológico em geral expressam a necessidade de uma profunda transformação da humanidade em direção a uma maior solidariedade e cooperação entre culturas, nações, indivíduos e espécies. (MELO, 2012, p. 38; 2019, p. 03).
\end{abstract}

Colocadas nesses termos, as decisões necessárias para a governabilidade da crise ecológica e a consequente realização do desenvolvimento sustentável podem perfeitamente ser interpretadas a partir de uma nova teoria da ação social, com uma maior conscientização e com uma nova ordem política. Para Viola (1995, p.11), "o contínuo agravamento da crise ecológica nas últimas décadas expressa de forma clara que a ação política atual não é mais congruente com a ordem existente". Segundo Melo (2012, p. 39; 2019, p. 03), "a ordem é entendida como o conjunto de fatores que garantem a convivência e a evolução humana", com isso, os valores, as práticas e as instituições em vigor já não produzem "ordem", favorecendo, muito mais, à "desordem".

O momento mais dramático da política mundial depois da guerra fria é a ausência de articulação entre o modelo de desenvolvimento econômico e de desenvolvimento ecológico necessário à sobrevivência da espécie humana. Esta foi a grande preocupação da Conferência das Nações Unidas sobre o Meio Ambiente e o Desenvolvimento (UNCED-92) e do Fórum Global, realizado no Rio de Janeiro.

Viola e Leis (1995, p.28) afirma que a convergência entre ecologia e economia não é tarefa fácil; ela exige muito mais que o uso de uma razão instrumental capaz de tomar decisões adequadas, tal como sugere o neoliberalismo com sua reivindicação da eficiência intrínseca do mercado. Segundo esse autor, ela 
demanda uma mudança profunda do comportamento e da mentalidade de todos os atores, sejam estes pertencentes ao mercado, ao Estado ou à sociedade civil. A ecologia exige que a Terra seja considerada como um bem comum e, em consequência, que a humanidade busque e encontre valores de convergência global, com maior poder de persuasão que os interesses particulares existentes, a fim de permitir o surgimento de instituições e regras às quais a diversidade de atores, aceite se sujeitar (tornando realista, em vez de falsas, as utopias de transformação). A importância da educação ambiental na política mundial consiste, precisamente, em tornar amplamente visível e inegável a necessidade de mudança, de ajuste entre a realidade, as consciências e as expectativas.

Por ocasião da Conferência das Nações Unidas sobre o Meio Ambiente e o Desenvolvimento (UNCED-92), cidadãos representando instituições de mais de cento e setenta países assinaram tratados nos quais se reconhece o papel central da educação para a "construção de um mundo socialmente justo e ecologicamente equilibrado", o que requer "responsabilidade individual e coletiva em níveis local, nacional e planetário" (MEC, PARÂMETROS CURRICULARES NACIONAIS TEMAS TRANSVERSAIS, 1998, p.181). Conforme Moraes (2004, p.34), é isso que se espera da Educação Ambiental no Brasil, assumida como obrigação nacional pela Constituição promulgada em 1988.

Para Melo (2012; 2019),

Todas as recomendações, decisões e tratados internacionais sobre o tema evidenciam a importância atribuída por lideranças de todo mundo para a Educação Ambiental como meio indispensável para conseguir criar e aplicar formas cada vez mais sustentáveis de interação sociedade/natureza e soluções para os problemas ambientais. Evidentemente, a educação sozinha não é suficiente para mudar os rumos do planeta, mas certamente é condição necessária para isso. (MELO 2012, p. 39; 2019, p. 03).

Nesse contexto, fica evidente a importância de educar a população mundial e os brasileiros para que ajam de modo responsável e com sensibilidade, conservando o ambiente saudável no presente e para o futuro; para que saibam exigir e respeitar os direitos próprios e os de toda comunidade, tanto local como internacional; e para que se modifiquem tanto interiormente, como pessoas, quanto nas relações com o ambiente.

A preocupação em relacionar a educação com a vida do aluno - seu meio, sua comunidade - vem crescendo especialmente desde a década de 60 no Brasil. Exemplo disso são atividades como os "estudos do meio". Porém, a partir da década de 70 , com o crescimento dos movimentos ambientalistas, passou-se a adotar 
explicitamente a expressão "Educação Ambiental" para qualificar iniciativas de universidades, escolas, instituições governamental e não governamental por meio das quais se busca conscientizar setores da sociedade para questões ambientais. Segundo Moraes (2004, p.66), um importante passo foi dado com a Constituição de 1988, quando a Educação Ambiental se tornou exigência a ser garantida pelos governos federal, estaduais e municipais (Art. 225, $\S 1^{\circ}, \mathrm{VI}$ ).

De acordo com a Constituição (1988, Art. VI),

Todos têm direito ao meio ambiente ecologicamente equilibrado, bem de uso comum do povo e essencial à sadia qualidade de vida, impondo-se ao Poder Público e à coletividade o dever de defendê-lo e preservá-lo para as presentes e futuras gerações. Para assegurar a efetividade deste direito, incumbe ao poder público "promover a Educação Ambiental em todos os níveis de ensino e a conscientização pública para a preservação do meio ambiente".

Neste final de século, de acordo com o depoimento de vários especialistas que vêm participando de encontros nacionais e internacionais, o Brasil é considerado um dos países com maior variedade de experiências em Educação Ambiental, com iniciativas originais que, muitas vezes, se associam a intervenções na realidade local. Portanto, qualquer política nacional, regional ou local que se estabeleça deve levar em consideração essa riqueza de experiências, investir nela e não inibi-la ou descaracterizar sua diversidade.

Segundo Melo (2012; 2019),

É necessário ainda ressaltar que, embora recomendada por todas as conferências internacionais, exigida pela Constituição e declarada como prioritária por todas as instâncias de poder, a Educação Ambiental está longe de ser uma atividade tranquilamente aceita e desenvolvida, porque implica mobilização por melhorias profundas do ambiente, e nada inócuas. Ao contrário, quando bem realizada, a Educação Ambiental leva a mudanças de comportamento pessoal e a atitudes e valores de cidadania que podem ter importantes consequências sociais o que implica em mudanças no espaço geográfico. (MELO 2012, p.40; 2019, p.04).

O debate internacional de concepções e práticas em Educação Ambiental resultou na elaboração do "Tratado de Educação Ambiental para Sociedades Sustentáveis e Responsabilidade Global', de caráter não-oficial, durante o Fórum das Organizações Não-Governamentais (ONGs), no Eco-92. Nele, foram delineados princípios e diretrizes gerais para o desenvolvimento de trabalhos com a temática Meio Ambiente. Faz parte desse conjunto de idéias de que não se trata de ensinar de forma acrítica os conceitos da ciência da ecologia ou simplesmente reduzir a Educação Ambiental a uma visão esotérico-existencial. Essa dualidade constitui uma extrema simplificação. 
Para Melo (2012; 2019),

Trata-se de desenvolver o processo educativo, contemplando tanto o conhecimento científico como os aspectos subjetivos da vida, que incluem as representações sociais, assim como o imaginário acerca da natureza e da relação do ser humano com ela. Isso significa trabalhar os vínculos de identidade com o entorno socioambiental. (MELO 2012, p.40; 2019, p.04).

Com isso quando se inclui também a sensibilidade, a emoção, sentimentos e energias se obtêm mudanças significativas de comportamento. Como Leis (1995) sintetizou a educação ambiental "é algo essencialmente oposto ao adestramento ou à simples transmissão de conhecimentos científicos, constituindo-se num espaço de troca desses conhecimentos, de experiências, de sentimentos e energia”.

De acordo com Melo (2012; 2019),

Para que o mercado possa atender as exigências ecológicas faz-se necessário encontrar fortes motivos para descolonizar a sociedade de valores e comportamentos individualistas, privilegiando valores coletivos. $\mathrm{O}$ grande desafio da educação ambiental é demonstrar que tem a capacidade ou potencialidade suficiente para produzir essa transformação moral da sociedade moderna. (MELO 2012, p.40; 2019, p.04).

O ambientalismo que começa a surgir a partir da segunda metade do século XX responde a uma situação similar à vivida em séculos anteriores, com a diferença de que agora a expansão do mercado está se realizando por cima das barreiras nacionais e em um planeta bastamente habitado. Neste contexto, o contramovimento defensivo ao mercado é de caráter fundamentalmente global e não pode privilegiar as questões social e nacional, concentrando mais sua atenção na relação sociedade-natureza, na degradação de um meio ambiente que agora é percebido com uma base de recursos finitos que estabelecem severos limites a um crescimento econômico contínuo e à própria reprodução da espécie humana.

O poder transformador do mundo contemporâneo encontra-se, precisamente, na forte ancoragem da educação ambiental no mundo vivido. Para Melo (2012; 2019),

A eficácia transformadora da educação ambiental se realiza na prática de um equilíbrio autêntico entre forças e princípios do realismo e idealismo. Uma sociedade planetária ecologicamente orientada supõe um mundo melhor, definido não apenas a partir de uma transformação instrumental da realidade, mas também de uma transformação da subjetividade humana, fazendo aflorar a verdadeira cidadania entre os homens, uma vez que esses desempenham seus deveres para com o Estado que pertencem e colocam os interesses da humanidade acima dos da pátria, tornando-se cidadãos do mundo. (MELO 2012, p. 41; 2019 p. 05).

No Brasil, a Lei № 9.795, de 27 de abril de 1999, regulamentada pelo Decreto № 4.281, de 25 de junho de 2002, dispõe sobre a Educação Ambiental, institui a 
Política Nacional de Educação Ambiental e dá outras providências. De acordo com o Artigo $1^{\circ}$ dessa Lei,

Entende-se por educação ambiental os processos por meio dos quais o indivíduo e a coletividade constroem valores sociais, conhecimentos, habilidades, atitudes e competências voltadas para a conservação do meio ambiente, bem de uso comum do povo, essencial à sadia qualidade de vida e sua sustentabilidade.

Para Melo (2019, p.05), “a Educação Ambiental, por si só, não pode resolver os problemas ambientais, mas é um dos principais instrumentos para promover a consciência da importância do meio ambiente na qualidade de vida". Foi com base dessa compreensão que se criou projetos interdisciplinares, em que a idéia central é detectar a influência dos conhecimentos adquiridos durante o processo educativo na convivência da população com o meio ambiente. Tendo como exemplo o projeto desenvolvido em uma escola pública do município de Fortaleza, que segundo Melo (2019), "no projeto se preparou e usou um inseticida natural, desenvolvido à base de Angico (Anadenanthera macrocarpa), para combater as formigas cortadeiras (Saúvas) na horta da Escola", como forma de recuperação de áreas degradadas e como contribuição à educação ambiental.

De acordo com Melo (2019),

A Escola Pública é uma área que guarda uma grande particularidade expressa por sua diversidade de alunos e exige conhecimentos, adoção de tecnologias e definição de prioridades apropriadas à sua realidade para que se alcance um nível de conhecimento suficiente, que garanta um padrão de qualidade de vida à sua população. (MELO 2019, p.05).

$\mathrm{Na}$ busca dessa garantia de vida é necessário desenvolver trabalhos pedagógicos utilizando a Educação Ambiental para os alunos, com o propósito de transmitir a visão correta sobre a área na qual a escola está localizada e que muitos dos alunos residem. Espera-se que, com base dos princípios da Educação Ambiental, a aquisição de novos valores, técnicas e atitudes incentivem os alunos da Escola Pública a uma mudança de comportamento em relação à utilização dos recursos naturais e a um manejo adequado das técnicas de proteção ambiental, visando à preservação do meio ambiente e, consequentemente, à melhoria de suas condições de vida e moradia.

Nessa visão a agroecologia é um termo novo para uma prática já utilizada por povos ancestrais, em que é possível aproveitar pequenas áreas de propriedades dedicadas à agricultura familiar, acoplado a recuperação ambiental.

De acordo com Melo (2015), 
Os sistemas agroflorestais sustentáveis de uso da terra, também conhecido como SAF's, combinam sequencialmente, o plantio de culturas anuais com plantas nativas e exóticas, para tanto, faz-se necessário um manejo adequado do solo, desde sua preparação à sua utilização, sem o uso de produtos químicos. (MELO 2015, p. 236).

Neste caso o fertilizante para o solo na horta da Escola pode ser realizado com o reaproveitamento da areia do formigueiro das saúvas, que possuem um papel importante na natureza, porque quando escavam o chão, para construir formigueiros, afofam a terra e, trazem materiais transportados do horizonte subsuperficial para a superfície do solo, rico em nutrientes e essenciais para a fertilização do solo.

Ainda segundo Melo (2015),

Seria importante realizar um estudo de caso, em que a principal preocupação fosse com o significado que têm as ações e os eventos para a área, enfatizando que é necessário por parte dos sistemas educacionais e das políticas públicas, estimularem a difusão dos sistemas agroflorestais e manejo florestal sustentável (SAF's). (MELO 2015, p. 230).

Não se pretende com esta análise apenas acumular informações técnicas sobre a agroecologia na área da horta escolar. Tem-se a pretensão de fornecer ao leitor o desejo de elaborar reflexões a partir das informações colhidas, fornecendo subsídios para outros aprofundamentos posteriores. Acredita-se que se as pessoas adotarem conscientemente alguns princípios elementares de comportamento com relação ao ambiente como cumprirem as normas de plantio e de extensão da prática do fertilizante natural, pode-se alterar de maneira significativa a atual tendência de comprometimento da qualidade de vida. Para que isso aconteça, é vital divulgar informações sobre a presente situação do ambiente e sobre o que é preciso fazer para recuperá-lo.

\section{A pesquisa do tipo etnográfico em educação}

Tendo como opção metodológica uma abordagem de pesquisa qualitativa, de acordo com Melo (2012, p. 41; 2019, p. 06), "esta proposta de trabalho busca respostas, tanto individual quanto coletiva, de forma sistemática e persistente". Para o autor citado,

Neste processo de busca as respostas são expostas à discussão, à crítica e ao debate para que o conhecimento venha se consolidar. Esta pesquisa não aceita que a realidade seja algo externo ao sujeito, valorizando a maneira própria de entendimento da realidade pelo indivíduo. Busca a interpretação em lugar da mensuração, a descoberta em lugar da constatação, valoriza a indução e assume que fatos e valores estão intimamente relacionados, tornando-se inaceitável uma postura neutra do pesquisador. (MELO, 2012, p. $41 ; 2019$, p. 06). 
Com base nesses princípios, a pesquisa qualitativa defende uma visão holística dos fenômenos, isto é, leva em conta todos os componentes de uma situação em suas interações e influências recíprocas. Trata-se de um estudo de caso etnográfico porque a principal preocupação é com o significado que têm as ações e os eventos para as pessoas ou os grupos estudados. Alguns desses significados são diretamente expressos pela linguagem, outros são transmitidos indiretamente por meio das ações, ambos descritos e avaliados pelo pesquisador.

A experiência do reaproveitamento da areia de formigueiro em fertilizante na horta escolar foi uma pesquisa do tipo etnográfico em educação porque: fez uso das técnicas que tradicionalmente são associadas à etnografia, ou seja, a observação participante, a entrevista intensiva e a análise de documentos; houve interação constante entre o pesquisador e o objeto pesquisado, ou seja, o pesquisador foi o instrumento principal na coleta e na análise dos dados; houve ênfase no processo, no que estava ocorrendo e não no produto ou nos resultados finais; houve preocupação com o significado, com a maneira própria com que as pessoas vêem a si mesmas, as suas experiências e o mundo que as cerca, levando o pesquisador a apreender e retratar essa visão pessoal dos participantes; realizou-se um trabalho de campo, onde o pesquisador se aproximou de pessoas, situações, locais, eventos, mantendo com elas um contato direto e prolongado; houve a descrição e a indução e, por fim, a formulação de hipóteses, conceitos, abstrações, teorias e sua testagem.

Para isso, o pesquisador fez uso de um plano de trabalho aberto e flexível, em que os focos da investigação foram constantemente revistos, as técnicas de coleta reavaliadas, os instrumentos reformulados e os fundamentos teóricos repensados. Esse tipo de pesquisa visa à descoberta de novos conceitos, novas relações e novas formas de entendimento da realidade.

Como referência empírica foi tomada a experiência pedagógica do reaproveitamento da areia de formigueiro em fertilizante natural na horta observada em uma escola pública em um bairro da periferia de Fortaleza, com turmas do Ensino Fundamental.

Como fonte primária foi utilizada o depoimento, coletado através de entrevistas, com alunos sobre esta experiência. 


\section{A experiência do reaproveitamento da areia de formigueiro em fertilizante natural na horta de uma escola pública}

Em uma escola pública na cidade de Fortaleza, segundo Melo (2019, p. 06), "foi realizado com grupos de estudantes do $8^{\circ}$ e 9ำ ano, um projeto para se combater as formigas cortadeiras (Saúvas) na horta da Escola com um inseticida natural à base de Angico (Anadenanthera macrocarpa)". Após o combate às formigas cortadeiras foi proporcionado aos estudantes um projeto para o reaproveitamento da areia de formigueiro em fertilizante natural e utilizar na horta escolar como forma de recuperação do solo e como contribuição à educação ambiental.

Para que o assunto 'fertilizante natural na horta escolar' fosse levado até os grupos de alunos, utilizou-se como base o projeto de Melo (2015, p.126) intitulado "a agroecologia e o reflorestamento como contribuição à educação ambiental", sendo dividido nas etapas que se seguem:

a) identificando as informações do grupo sobre o tema: foi realizado um questionário com perguntas subjetivas e pessoais, que objetivou fazer um levantamento dos conhecimentos e pré-conceitos existentes entre os integrantes do grupo de trabalho. (Quadro 01).

Quadro 01 - Levantamento dos Conhecimentos sobre Educação Ambiental.

\begin{tabular}{|l|c|c|}
\hline \multicolumn{1}{|c|}{ Perguntas } & \multicolumn{2}{|c|}{ Conhecimento dos Alunos } \\
\hline O que é fertilizante natural? & $80 \%$ Não Conhece & $\begin{array}{c}20 \% \text { Tem } \\
\text { Conhecimento }\end{array}$ \\
\hline $\begin{array}{l}\text { O homem é capaz de usar, sem } \\
\text { abusar a natureza? }\end{array}$ & $80 \%$ Não & $20 \%$ Sim \\
\hline $\begin{array}{l}\text { Você se acha responsável pela } \\
\text { natureza? }\end{array}$ & \multicolumn{2}{|c|}{$100 \%$ Sim } \\
\hline
\end{tabular}

Fonte: MELO (2019 e 2020). Org.: Elaborado pela autora.

Diante das respostas obtidas, observou-se que, no que se refere ao que é fertilizante natural, a maioria não sabia do que se tratava. A minoria, que conhecia algo sobre o tema respondeu: "é qualquer tipo de fertilizante feito com produtos da natureza"; "é qualquer produto da natureza para enriquecer o solo". Com isso, entendia que o fertilizante natural é um dos pontos principais para a proteção da natureza e para a sobrevivência do próprio homem, sendo importante utilizá-lo no tratamento da horta escolar.

$\mathrm{Na}$ opinião de cada entrevistado sobre o homem ser capaz de usar, sem abusar a natureza, observou-se que, a maioria das respostas foi "não", o que segundo Melo (2019, p. 7), "demonstra uma compreensão de que o progresso implica, obrigatoriamente, na destruição da natureza pelo homem". Entretanto, é 
preciso registrar também, que se verificou entre os alunos entrevistados certa compreensão de que a exploração da natureza articula-se com questões culturais e socioeconômicas, sinalizando uma visão mais crítica e menos determinista por parte desses. Apenas uma minoria respondeu que o homem é capaz de usar a natureza sem abusar, que de acordo com Melo (2019),

Para isso acontecer é preciso conscientizar o homem da importância da natureza para sua própria sobrevivência. Para isso é preciso zelar por ela, evitando agressões como: queimadas, utilização de agrotóxicos, poluição do ar e de rios entre outras, porque o homem é essencialmente inteligente, quando capaz de progredir sem destruir. $\operatorname{MELO}(2019$, p. 7).

Quando analisada as respostas da última pergunta, se o entrevistado se acha responsável pela natureza, por unanimidade todos responderam que "sim".

b) aula de campo: seguindo uma atividade interdisciplinar de Melo (2019, p. 7), que uniu geografia, ciências e matemática, o objetivo foi realizar uma observação "in loco" do tamanho do formigueiro que existia na área escolar, próximo da sua horta. Realizou-se a medida do raio do formigueiro para, em seguida calcular o seu diâmetro. (Figuras 01 e 02).

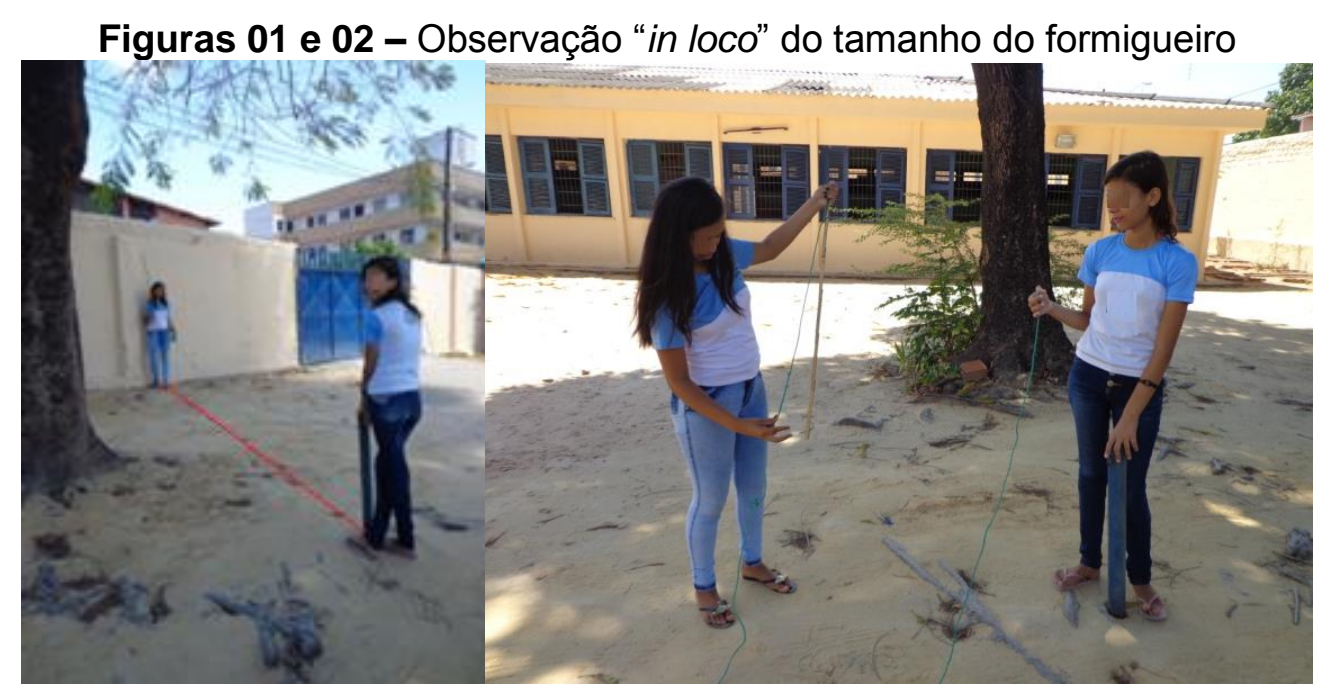

Fonte: MELO (2019). Org.: Elaboradas pela autora.

c) oficina geográfica: com o objetivo de mostrar a importância da preparação e uso do fertilizante natural na horta escolar, a oficina geográfica, com duração de duas horas, foi organizada por equipes de $8^{\circ}$ e $9^{\circ}$ ano. Neste momento os alunos foram orientados para levarem areia comum e esterco de gado. Seguindo a experiência de Melo (2015),

Para o reflorestamento em cada viveiro houve a preparação do solo, com uma adubação especial à base de areia de formigueiro, que são materiais transportados, pelas formigas operárias, do horizonte sub-superficial para a superfície do solo, rico em nutrientes; areia comum, ou seja, terra da região e esterco de gado, todos misturados e peneirados e, em seguida realizou-se 
a plantação das sementes, após a quebra de dormência. (MELO, 2015, p. 137).

No pátio de lazer, com o material, todos os alunos colocavam a areia de formigueiro em um círculo e misturavam com a areia comum e o esterco de gado. Com isso misturavam até dar o ponto de adubo. Após o adubo pronto, cada turma, depositava em um carrinho de mão, onde eram colocadas dentro dos canteiros da horta escolar. (Figuras 03, 04 e 05).

Figuras 03, 04 e 05 - Preparação do Fertilizante Natural

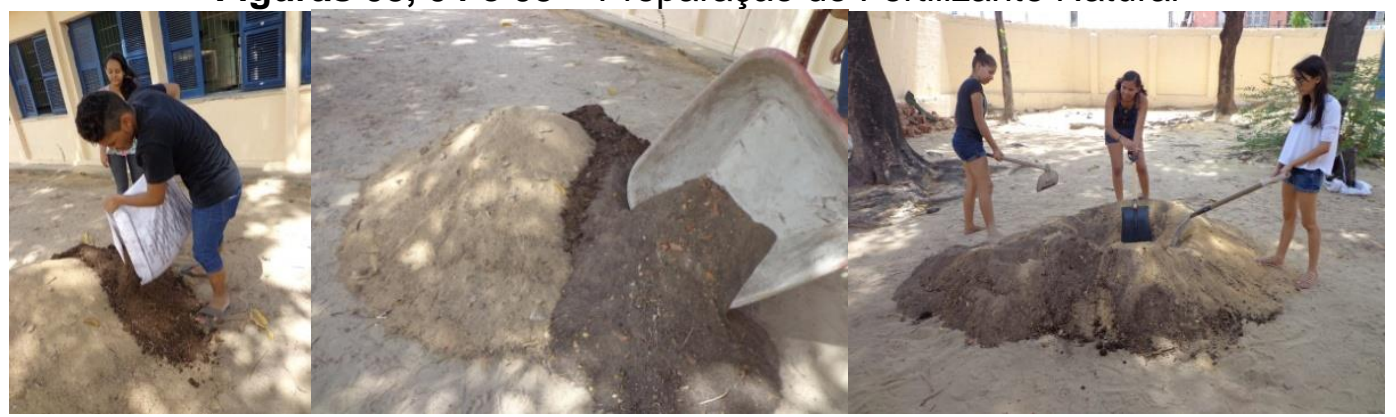

Fonte: MELO (2019). Org.: Elaboradas pela autora.

Ao final, com os canteiros prontos e, através da observação começaram a perceber que "a horta estava semipronta", fato esse, que constatou que diante deles estava um belíssimo trabalho feito com produto natural e com o esforço pessoal, e muito pouco gasto com material. Com isso começaram a perceber a importância econômica do fertilizante natural. (Figuras 06 e 07).

Figuras 06 e 07 - Preparação dos Canteiros com Fertilizante Natural

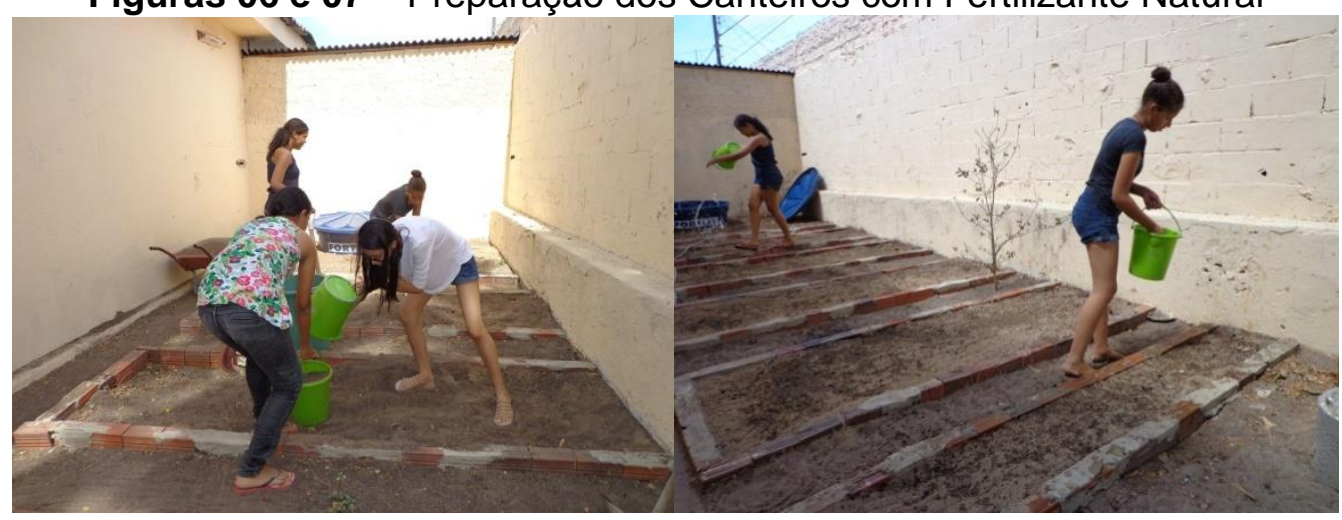

Fonte: MELO (2019). Org.: Elaboradas pela autora.

d) pesquisa sobre o fertilizante natural: dando continuidade ao processo de formação e conscientização dos alunos, articulando teoria e prática, desenvolveu-se uma atividade de pesquisa sobre o fertilizante natural. Essa etapa teve como objetivo identificar a fertilização do solo para o plantio de hortaliças. O tema foi 
desenvolvido no Laboratório de Informática Educativa - LIE, com trabalhos diferenciados, como mostra alguns resumos:

Equipe 1- Fertilizantes naturais são todas aquelas substâncias que enriquecem o solo de nutrientes e que não passaram por nenhum processo artificial na sua elaboração. Possuem em sua composição, somente produtos naturais, sem haver algum tratamento químico. O exemplo é a utilização do "esterco" de gado para a fertilização da terra. O fertilizante natural para o solo na horta da Escola pode ser realizado com o reaproveitamento da areia do formigueiro das saúvas, que possuem um papel importante na natureza, porque quando escavam o chão, para construir formigueiros, afofam a terra e, trazem materiais transportados do horizonte subsuperficial para a superfície do solo, rico em nutrientes e essenciais para a fertilização do solo juntamente com a Matéria Orgânica. De acordo com dados da UFC (1993), "a Matéria Orgânica (M.O.) do solo é constituída pelos resíduos de origem vegetal ou animal depositados no solo, não decompostos ou em diferentes estágios de decomposição". Segundo Melo (2013), na área onde é realizada a agricultura, após a colheita do milho e do feijão, a criação de bovinos e ovinos é solta para comer a pastagem e fica durante quatro meses, liberando húmus na área, o que serve como adubo. O húmus é a parte da matéria orgânica que perdeu, por decomposição, as suas propriedades originais. A matéria orgânica, bem como, 0 húmus exerce influências benéficas sobre as propriedades físicas, químicas e biológicas do solo. (UFC, 1993). (Figura 08).

Figura 08 - Húmus como Fertilizante Natural

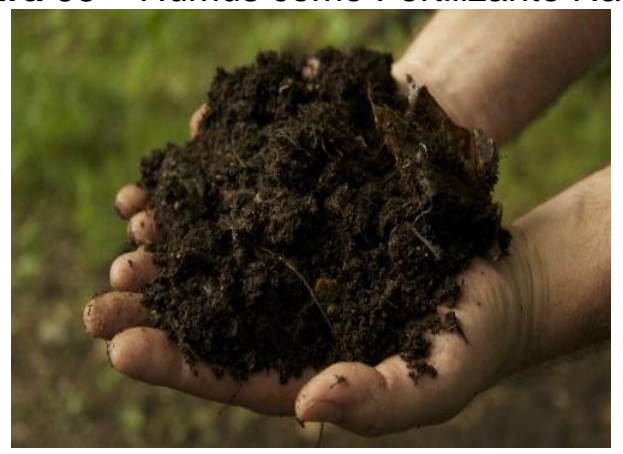

Fonte: MELO (2019). Org.: Adaptado pela autora:

Disponível em: < http://agronegociointerior.com.br/compostagem/>. Acesso em: 07 mai. 2020.

Equipe 2 - Na área do semiárido, segundo Araújo Filho \& Crispim (2002), surge uma vegetação xerófila, de fisionomia e florística variada, denominada caatinga. $O$ semiárido nordestino tem a maior parte de seu território ocupado por essa vegetação, que expressa uma condição de sobrevivência ligada a um ambiente seco, com deficiência hídrica, onde a água disponível para as plantas procede 
unicamente do curto período da estação chuvosa. O termo caatinga é uma denominação típica do Nordeste semiárido brasileiro e tem origem indígena (caa mata; tinga - branca aberta), que significa "mata branca". Na classificação da vegetação, de acordo com Araújo Filho \& Crispim (2002), caatinga é um complexo vegetacional constituído, especialmente, de espécies arbustivas e arbóreas de pequeno porte, geralmente dotadas de espinhos, sendo caducifólias, em sua maioria, perdendo suas folhas no início da estação seca.

Após realizar uma observação in loco, na área da horta escolar, foram identificadas de acordo com Freitas (2004), as espécimes listadas. (Quadro 02).

Quadro 02: Espécies arbóreas

\begin{tabular}{|l|l|}
\hline NOME CIENTÍFICO & NOME POPULAR \\
\hline Anadenanthera macrocarpa & Angico \\
Mangifera indica & Mangueira \\
Eugenia SP & Jambo \\
\hline
\end{tabular}

Fonte: FREITAS (2004). MELO (2015).

A caatinga, segundo Maia (2004), tem fornecido ao longo dos séculos inúmeros produtos que servem para o consumo do povo sertanejo e, também, que podem ser comercializados. Entre eles encontram-se: madeiras para os mais variados usos, desde madeiras super leves até madeiras muito pesadas; forragens para bovinos, ovinos, caprinos, equinos, e outros; caça e mel de abelhas, plantas alimentícias (frutíferas e as que fornecem raízes e folhas como verduras), plantas medicinais para remédios caseiros, produtos de higiene corporal, óleos comestíveis e industriais, substâncias para tintas, inseticidas e matérias-primas para muitos outros produtos do uso diário, entre elas o Angico. (Quadro 03). 


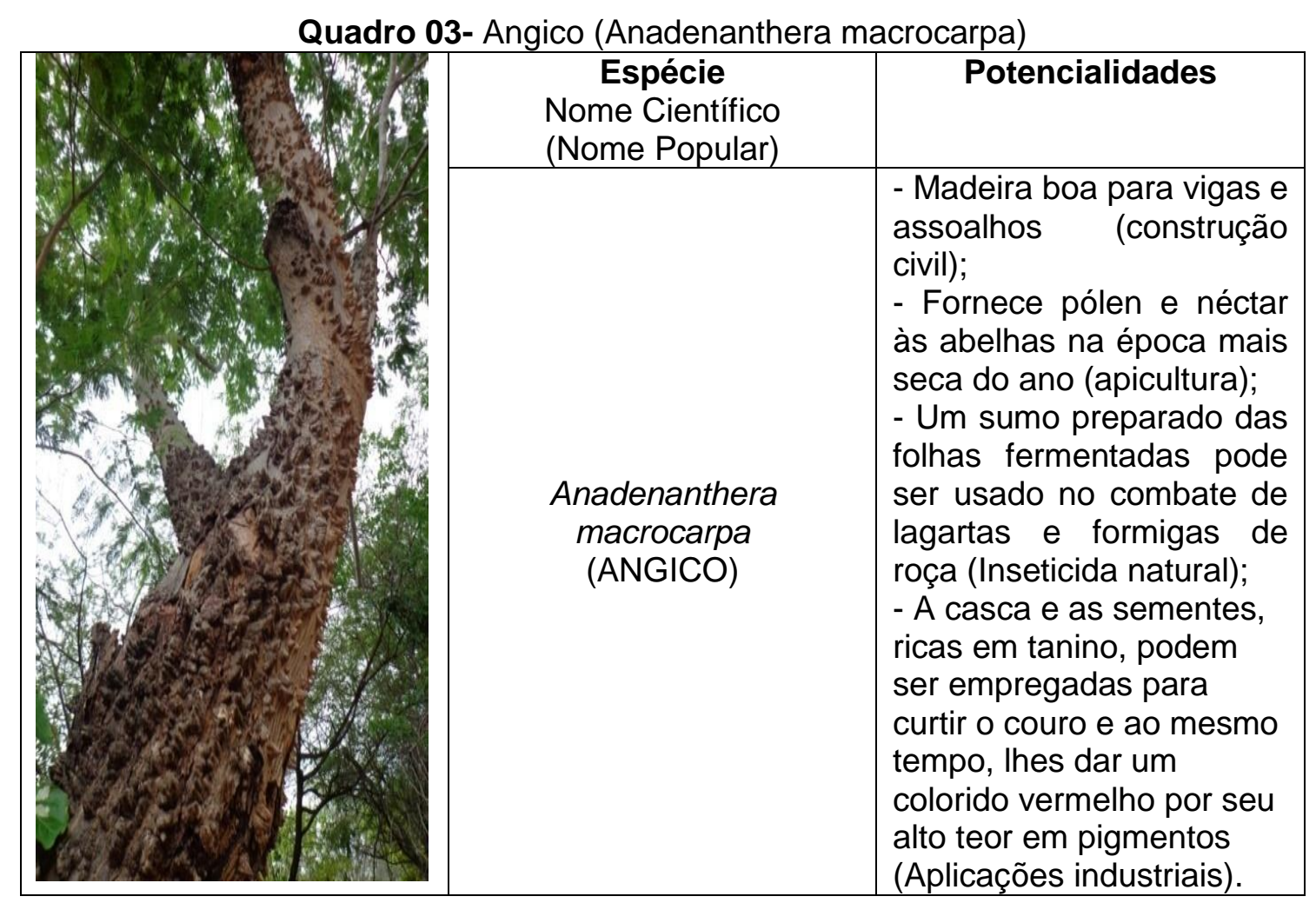

Localidade: Sertão dos Inhamuns/Município de Parambu/Ceará.

Fonte: MELO (2015).

Equipe 3 - Segundo Melo (2019, p. 9 e 10), no território brasileiro existe um nome próprio e bem específico para a sociedade das formigas, os "formigueiros". Esses espaços subterrâneos podem reunir entre centenas até milhares de formigas; tudo vai depender da sua organização e do seu próprio tamanho, como também das tarefas a serem desempenhadas. A formiga mais conhecida em âmbito nacional é a de gênero Saúva, que possue papel importante na natureza, porque: escava o chão, afofa a terra e, traz folhas picadas para seu ninho contribuindo para a fertilização do solo. É importante afirmar que: "as formigas não se alimentam desses pedaços de folhas". Mas, por outro lado, elas fazem uso dos pedaços de folhas como adubo para as criações subterrâneas e internas de fungos, ou seja, para alimentar uma colônia de fungos, chamados "Rhozites gongylophora". O fungo, no caso, é a principal fonte de alimento para esses insetos. É isso que acontece na preparação da alimentação das formigas Saúvas. Tanto os inseticidas naturais, como os tóxicos não matam diretamente a formiga, eles destroem o fungo, que são alimento da formiga e, sem alimento, a formiga não sobrevive. (Figura 09). 
Figura 09 - Passo a passo da alimentação das Saúvas

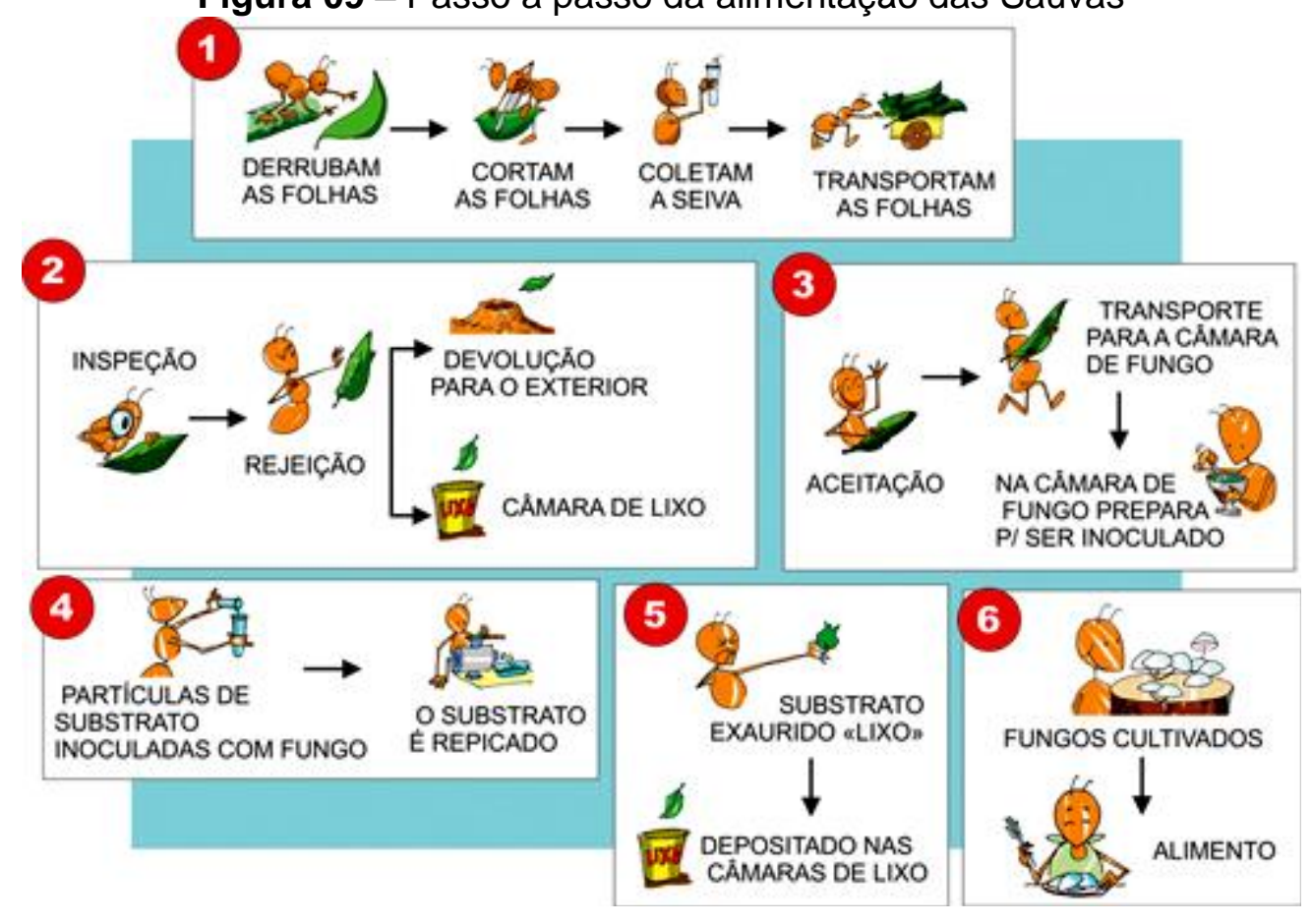

Fonte: MELO, 2019. Org.: Adaptado pela autora:

Disponível em: < http://www.geosaberes.ufc.br/geosaberes/article/view/661 >. Acesso em: 07 mai. 2020.

Equipe 4 - A horta ou horto é um local em que são cultivados legumes e hortaliças. Nela também podem plantar-se temperos e ervas medicinal. As hortas geralmente localizam-se em um terreno que recebe sol o dia todo, com terra fértil que possa ser adubada. A horta urbana é aquela cultivada em um espaço coletivo ou doméstico em áreas urbanas. Trata-se de umas das atividades que englobam a agricultura urbana, que tem como principais objetivos facilitar a distribuição dos alimentos nas cidades, diminuir o consumo de agrotóxicos e contribuir com o meio ambiente. As hortas urbanas desmistificam aquela ideia de que hortas só dão certo em propriedades rurais. Uma horta urbana pode ocupar pequenos ou grandes espaços horizontais ou ser plantada verticalmente com o auxílio de garrafas pet, vasos, canos, latas, entre outros materiais. As plantações horizontais podem ser organizadas em canteiros. Os canteiros são criados para facilitar o plantio de algumas espécies, como alface, cenoura, alho, entre outras, especialmente quando o desenvolvimento inicial é relativamente lento. Por meio dos canteiros e da criação de "ruas" entre eles, a locomoção pela horta e o trato com as plantas ficam facilitados, principalmente em momentos como a capina. Além disso, os canteiros evitam o acúmulo de água entre as plantas, sobretudo se o plantio ocorrer em uma baixada ou área propensa ao acúmulo de água. A largura dos 
canteiros e das "ruas" depende do tamanho do terreno disponível. Entretanto, deve ser pensada de modo a facilitar a realização dos trabalhos manuais como semeaduras, capinas e colheita. De modo geral, os canteiros podem variam de 90 cm a $120 \mathrm{~cm}$. Já as "ruas" ficam com a largura entre $30 \mathrm{~cm}$ e $50 \mathrm{~cm}$. (Figuras 10 e 11).
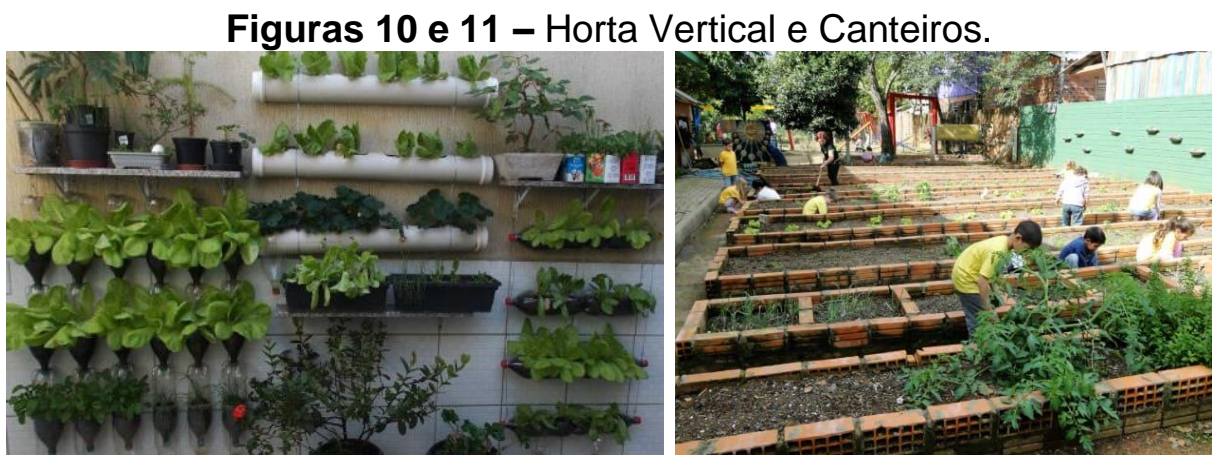

Fonte: MELO (2019). Org.: Adaptado pela autora:

Disponível em: < https://www.vivadecora.com.br/pro/arquitetura/hortas-urbanas/>. Acesso em: 07 mai. 2020.

e) apresentação dos trabalhos de equipe: Nos dias que se sucederam o trabalho interdisciplinar, que uniu a disciplina de geografia, ciências e arte/literatura foi essencial ao combinar, sequencialmente, a leitura das pesquisas sobre "fertilizante natural' para que houvesse o conhecimento e a fixação do conteúdo nele contido, bem como dos prejuízos e consequências provenientes da deficiência de nutrientes minerais nos solos e, em seguida, um grande debate em equipes foi desenvolvido.

Após a semana de debates, sobre o uso do fertilizante natural produzido de areia de formigueiro das formigas Saúvas, após o uso do inseticida natural, ficou claro, que deve existir uma relação dinâmica entre teoria e prática, mas a partir da realidade concreta do aluno e da escola e não de forma absolutamente mecânica. Com isso, percebeu-se que a preocupação dos alunos em relacionar a teoria (sobre o que eles sabiam a respeito do fertilizante natural e como utilizá-lo) com a prática se efetiva no momento no qual eles têm que reaproveitar a areia de um formigueiro real, combatido com inseticida natural, anotar suas ações e conclusões de preparação e uso do fertilizante natural na horta escolar e apresentar em uma sala de aula, onde deixam de ser simples expectadores e passam a agir e a mostrar conhecimento.

Como conclusão dessa etapa, foi destacado o tema "Preservação Ambiental: fertilizante natural na horta da escola", quando se apresentou as fotografias da "oficina geográfica" sobre a produção do fertilizante natural à base de areia de 
formigueiro, areia comum e esterco de gado, explicando como fazê-lo e como usálo, explanando como se realizou o planejamento coletivo para implantar o uso do fertilizante natural na horta da Escola, bem como a explicação das conclusões obtidas na "pesquisa sobre os nutrientes da areia de formigueiro" e da importância dos mesmos para o solo e para a vegetação enriquecendo a educação ambiental.

f) sistemas agroflorestais de uso da terra: partindo dos conhecimentos dos sujeitos envolvidos, tomou-se a decisão de trabalhar as questões necessárias ao entendimento da agroecologia, através dos sistemas agroflorestais sustentáveis (SAF's). Nesta etapa do trabalho, o objetivo foi mostrar a importância da areia do formigueiro das saúvas, combatido com 'inseticida natural' e essencial para a produção do fertilizante natural, sendo este possível de ser implantado na horta escolar.

Para a horta escolar em cada viveiro houve a preparação do solo, com uma adubação especial à base de areia de formigueiro, que são materiais transportados, pelas formigas operárias, do horizonte sub-superficial para a superfície do solo, rica em nutrientes; areia comum, ou seja, terra da região e esterco de gado, todos misturados e peneirados e, em seguida realizou-se a plantação das sementes. Com isso os estudantes chegaram a algumas conclusões, como: "o vegetal não se desenvolve normalmente se não obtiver os nutrientes que são necessários para o seu crescimento". "Os elementos minerais essenciais são: nitrogênio, fósforo, potássio, cálcio, magnésio, enxofre, boro, cloro, ferro, manganésio, zinco, cobre, molibidênio e níquel". "Os elementos não minerais essenciais, (elementos captados como gás ou água) são: hidrogênio, oxigênio e carbono". "Os elementos benéficos, que promovem o crescimento em várias plantas, mas que não são absolutamente necessários para que se complete o ciclo de vida da planta, ou que não age diretamente na planta: sílica, sódio, cobalto e selênio".

Destacaram, também, que: "os nutrientes indispensáveis são absorvidos pelas plantas em quantidades especificas necessárias para o seu desenvolvimento e podem ser divididos de acordo com a concentração relativa nos tecidos da planta em 'macronutrientes' e 'micronutrientes'. Esta divisão não significa que um nutriente seja mais importante do que outro, apenas que eles são necessários em quantidades e concentrações diferentes". (Quadro 04).

A deficiência de nutrientes minerais nos solos acarreta uma serie de problemas para a produção vegetal, causando alterações no metabolismo e no suprimento adequado do elemento. As plantas apresentam sintomas indicadores 
das deficiências. Estes indicadores dependem da função do elemento deficiente na planta e da mobilidade no vegetal. As deficiências de nutrientes das plantas têm vários sintomas observáveis os quais normalmente são semelhantes, independente da espécie da planta.

Quadro 04 - Nutrientes Indispensáveis para o Desenvolvimento dos Vegetais.

\begin{tabular}{|c|c|c|c|}
\hline \multicolumn{2}{|c|}{$\begin{array}{c}\text { MACRONUTRIENTES } \\
\text { Fazem parte de moléculas essenciais, } \\
\text { são necessários em grandes } \\
\text { quantidades e tem funcão estrutural. }\end{array}$} & \multicolumn{2}{|c|}{$\begin{array}{l}\text { MICRONUTRIENTES } \\
\text { Fazem parte das enzimas e tem função } \\
\text { reguladora, sendo necessários em } \\
\text { quantidades menores. }\end{array}$} \\
\hline $\begin{array}{l}\mathrm{N} \text { - Nitrogênio } \\
\mathrm{K} \text { - Potássio } \\
\text { Ca - Cálcio }\end{array}$ & $\begin{array}{l}\text { Mg - Magnésio } \\
\mathrm{P} \text { - Fósforo } \\
\mathrm{S}-\text { Enxofre }\end{array}$ & $\begin{array}{l}\mathrm{Cl}-\text { Cloro } \\
\mathrm{Fe}-\text { Ferro } \\
\mathrm{B}-\text { Boro } \\
\mathrm{Mn}-\text { Manaanês }\end{array}$ & $\begin{array}{l}\text { Zn - Zinco } \\
\mathrm{Cu} \text { - Cobre } \\
\text { Mo - Molibdênio }\end{array}$ \\
\hline
\end{tabular}

Fonte: MELO (2015).

O sintoma de deficiência de nutrientes mais comuns na maioria das plantas é a redução do crescimento, entretanto ocorrem outros sintomas como a mudança de coloração que apresentam padrões específicos, partindo da ponta da folha passando pela nervura central até a base, ou da margem para a nervura central, ou entre as nervuras.

Os sintomas de deficiência mineral podem aparecer nas folhas novas ou nas folhas mais velhas, mostrando a variação desses minerais no solo e por consequência na planta.

A horta escolar seguiu os sistemas agroflorestais sustentáveis de uso da terra (SAF's), em que combinou sequencialmente, o plantio de verduras e legumes sem a utilização de agrotóxicos realizando um manejo adequado de adubação e plantação. (Figuras 12, 13 e 14). 
Figuras 12, 13 e 14 - Plantação de Verduras na Horta Escolar.

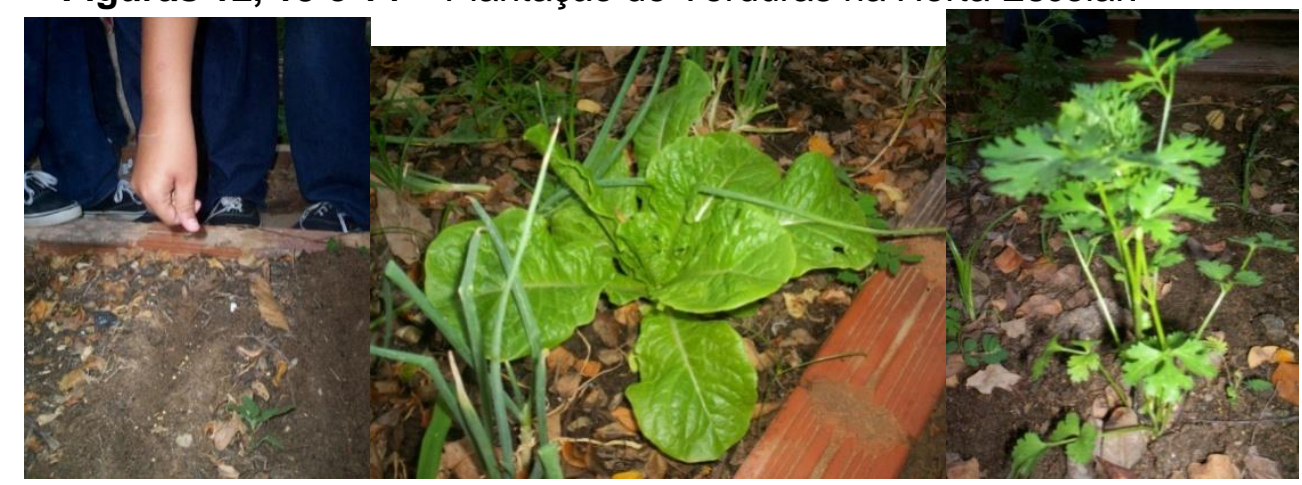

Fonte: MELO (2019). Org.: Elaboradas pela autora.

g) exposição do trabalho sobre reaproveitamento da areia de formigueiro em fertilizante natural na Exposição de Educação, Esporte e Cultura: no final do ano de 2016, a equipe do $8^{\circ}$ ano do Ensino Fundamental, apresentou o trabalho mostrando a importância do reaproveitamento da areia de formigueiro em fertilizante natural na horta escolar tendo como principal foco a proteção da natureza e do próprio homem. A exposição do trabalho, durante a semana inteira da exposição, demonstrou a preocupação dos alunos com a natureza e tentativa, dos mesmos, em conscientizar um maior número de pessoas. (Figura 15).

Figura 15 - Exposição do Trabalho sobre Fertilizante Natural.

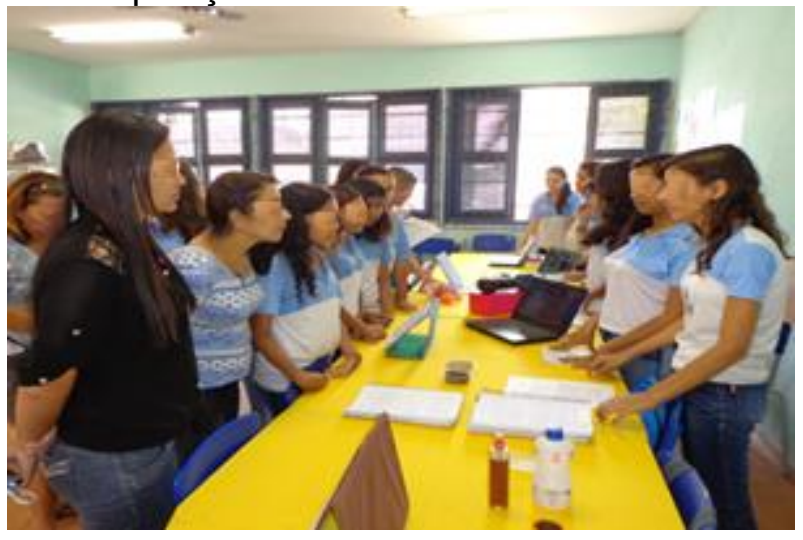

Fonte: MELO (2019). Org.: Elaborada pela autora.

h) participação no VII Seminário Cultura de Paz, Educação e Espiritualidade UFC: ao final das atividades do trabalho sobre o reaproveitamento da areia de formigueiro em fertilizante natural na horta escolar, o mesmo foi inscrito e selecionado para o VII Seminário Cultura de Paz, Educação e Espiritualidade na Faculdade de Educação da Universidade Federal do Ceará, em que foi apresentado, pelos alunos, na categoria "comunicação oral'. A síntese do trabalho encontra-se publicado nos Anais do "Grupo de Pesquisa Cultura de Paz, Juventudes e Docentes 
(UFC Cnpq)" no "Livro de Resumos do VII Seminário Cultura de Paz - 2016" no site https://ufcculturadepaz.webnode.com.br/.

O tema da "Roda de Conversa" tratou sobre a "Cultura de Paz, Saúde, Espiritualidade e Educação Ambiental'. Facilitada por Doutoras da UFC, a conversa girou em torno da aplicabilidade de projetos que garantam a cidadania plena e a preservação do meio ambiente.

Esta participação foi efetivada com o intuito de avaliar como o trabalho realizado contribuiu para a aprendizagem e a conscientização do aluno em relação ao tema. (Figura 16).

Figura 16 - Participação no VII Seminário Cultura de Paz, Educação e Espiritualidade.

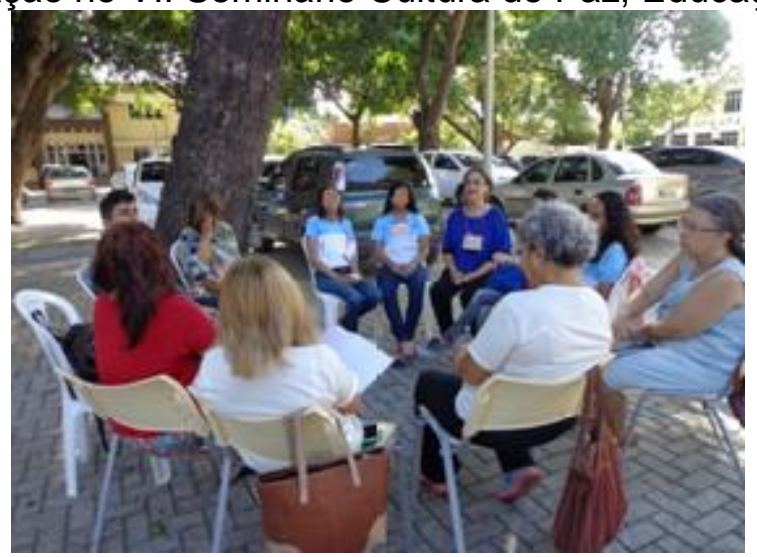

Fonte: MELO (2019). Org.: Elaborada pela autora.

As afirmações ministradas na "Roda de Conversa" no Seminário apontaram que o trabalho foi positivo uma vez que apresentavam um grau de conscientização e responsabilidade muito maior, não importando a série, conforme destaca os trechos selecionados: "Há receitas de fertilizantes naturais para combater a formiga cortadeira. Após estudos e pesquisas conseguimos desenvolver um 'fertilizante natural' com areia de formigueiro, este tendo sido combatido com ANGICO (Anadenanthera macrocarpa), areia comum e esterco de gado, finalizando um produto que pode salvar a natureza e salvar vidas”. A questão, sobre a sua responsabilidade para com a natureza, explicaram: "Somos responsáveis pela natureza. Ela, que é a fonte de toda a vida, está sendo destruída, porque no passar dos dias, nos esquecemos desta preciosa lição e não nos conscientizamos da nossa responsabilidade".

i) participação da VI Feira Municipal de Ciências e Cultura - SEARA/UFC: o trabalho sobre o "reaproveitamento da areia do formigueiro em fertilizante para 0 solo", inscrito e selecionado para a VI Feira Municipal de Ciências e Cultura, iniciativa da Secretaria Municipal de Educação e da Seara da Ciência da 
Universidade Federal do Ceará, em que foi apresentado, pelos alunos, na categoria "banner", com o objetivo central de apresentar os resultados de um experimento, que consiste em estudar um problema científico, social e educacional, usando o "Método Científico", mostrando o senso investigador científico de cada aluno.

O "banner" foi apresentado para todos os estudantes e profissionais, que se aproximavam, em que, as perguntas que surgiam sobre a preservação do solo e do meio ambiente obtinham respostas. (Figuras 17 e 18).

Figuras 17 e 18 - Participação na VI Feira Municipal de Ciências e Cultura - SEARA/UFC.
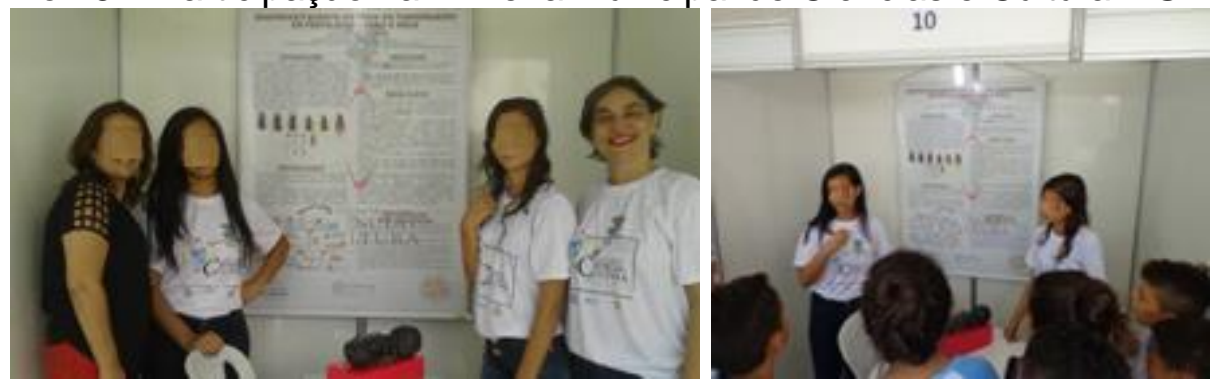

Fonte: MELO (2019). Org.: Elaboradas pela autora.

\section{Considerações Finais}

A experiência do reaproveitamento da areia de formigueiro em fertilizante natural como contribuição à educação ambiental, realizada com os alunos do Ensino Fundamental é considerada uma tentativa concreta e objetiva no sentido de articular teoria e prática. Desse modo, pode-se inferir que a mesma buscou ser criadora, caracterizando-se por uma forte preocupação com o espaço geográfico e o social.

A prática social é quem define as linhas de ação que deverá ser seguida, ou seja, o professor primeiro procura conhecer a realidade de seus alunos para poder agir e nunca pensa em jogar para eles conteúdos importados, recebidos prontos, elaborados verticalmente e que não condizem com sua realidade. Assim foi o caso da experiência do reaproveitamento da areia de formigueiro em fertilizante natural na horta de uma escola pública, onde se observou que no bairro em que a mesma tem sua sede e onde reside quase todo o seu corpo discente, o fator fertilizante natural nunca havia sido discutido, trazendo surpresa para alunos, moradores do bairro e docentes.

A prática pedagógica reflexiva é criadora e transformadora, ou seja, ela é capaz de produzir um novo homem, uma nova sociedade, um novo espaço geográfico e com isso uma nova realidade. É necessário que o professor seja consciente de tudo que o cerca, ele deve estar ciente de sua missão histórica, de 
suas finalidades, da estrutura da sociedade capitalista, do papel da escola dentro dessa sociedade, suas condições reais de trabalho e principalmente as possibilidades de transformações. Tudo isso tem que ser conhecido e analisado pelos professores e alunos que anseiam desenvolver uma visão crítica da realidade em que vivem. A despeito de todas essas dificuldades, a experiência mostrou que 0 alvo principal, ou seja, o reaproveitamento da areia de formigueiro em fertilizante natural na horta escolar como contribuição à educação ambiental dos alunos do Ensino Fundamental, no início atraído apenas pelo fator curiosidade e pela forma de como o assunto seria trabalhado, foi atingido, aumentando a conscientização sobre o tema, reforçando a importância da erradicação dos atos de exploração e devastação do meio ambiente e fortalecendo o conhecimento e a prática da agroecologia, criadora e transformadora, sendo capaz da preservação ambiental.

\section{REFERÊNCIAS}

ARAÚJO FILHO, J. A.; CRISPIM, S. M. A. Pastoreio combinado de bovinos, caprinos e ovinos em áreas de Caatinga no Nordeste do Brasil. In: CONFERÊNCIA VIRTUAL GLOBAL SOBRE PRODUÇÃO ORGÂNICA DE BOVINOS DE CORTE. UNIVERSITY OF CONTESTADO. Concórdia, 2002. Anais. Concórdia, Embrapa pantanal, 2002, p. 1-7.

BRASIL, Câmara dos Deputados. Decreto no 4.281, de 25 de junho de 2002.

EMENTA: Regulamenta a Lei no 9.795, de 27 de abril de 1999, que institui a Política Nacional de Educação Ambiental, e dá outras providências. Disponível em < http://www2.camara.leg.br/legin/fed/decret/2002/decreto-4281-25-junho-2002-459149norma-pe.html > Acessado em janeiro de 2020.

BRASIL, Ministério da Educação. Parâmetros Curriculares Nacionais - Geografia. Brasília: Ministério da Educação, 1998.

BRASIL, Ministério da Educação. Parâmetros Curriculares Nacionais - Temas Transversais. Brasília: Ministério da Educação, 1998.

BRASIL, Senado Federal. Constituição da República Federativa do Brasil. 2. ed. Brasília: Subsecretaria de Edições Técnicas, 1988.

BRASIL, Senado Federal. Conferência das Nações Unidas sobre Meio Ambiente e Desenvolvimento Humano - UNCED 92. Agenda 21. Brasília: Senado Federal, 1994.

FÓRUM GLOBAL 92. Tratado de educação ambiental para sociedades sustentáveis e responsabilidade local. Aprovado no Fórum Internacional das Organizações NãoGovernamentais e Movimentos Sociais no âmbito do Fórum Global Eco-92. Rio de Janeiro: Fórum das ONGs, 1992.

FREITAS, R.C. et. al. Flora da Caatinga. Fortaleza: Edições Demócrito Rocha; Associação Caatinga, 2004. 
MAIA. G. N. Caatinga: árvores e arbustos e suas utilidades. São Paulo: D\&Z Editora, 2004.

MELO, C. C. F. A Reciclagem do Lixo Urbano como Contribuição à Educação Ambiental no Ensino Fundamental. Monografia (Especialização em Metodologia do Ensino de Geografia) - Programa de Pós-Graduação em Educação - UECE, Fortaleza, 1999.

MELO, C. C. F. A Reciclagem do Lixo Urbano como Contribuição ao Ensino de Geografia. Universidade Federal do Ceará: Revista Geosaberes, Fortaleza, v. 3, n. 5, p. 37-46, jan./jun. 2012.

MELO, C. C. F. Reflorestamento como Indicador Ambiental: a Sustentabilidade no Riacho São Gonçalo Inserido na Bacia do Alto Jaguaribe. Universidade Estadual do Ceará: Revista GeoUECE, Fortaleza, v. 2, n. 2, p. 7-17, jan/jun. 2013.

MELO, C. C. F. Práticas Produtivas e de Conservação Ambiental no Reordenamento Territorial do Alto Jaguaribe - Ceará. Tese (Doutorado em Geografia) - Programa de PósGraduação em Geografia - UECE, Fortaleza, 2015.

MELO, C. C. F. A Agroecologia e o Reflorestamento como Contribuição à Educação Ambiental: o caso do Sítio São Gonçalo - 2000 A 2014. ACTA Geográfica, Boa Vista, v.9, n.19, p.126-145. jan./abr. de 2015. ISSN 1980-5772 e ISSN 2177-4307. Disponível em : < https://revista.ufrr.br/actageo/issue/view/151/showToc >. Acesso em 18 jan. 2020.

MELO, C. C. F. A experiência do inseticida natural na horta escolar como contribuição ao ensino de geografia. Geosaberes, Fortaleza, v. 10, n. 20, p. 1 - 14, jan/abr. 2019. ISSN 2178-0463. Disponível em: < http://www.geosaberes.ufc.br/geosaberes/article/view/661 >. Acesso em: 18 jan. 2020. DOI: https://doi.org/10.26895/geosaberes.v10i20.661.

MORAES, Alexandre de. Constituição do Brasil e Legislação Constitucional. Interpretada, São Paulo, n. 4, p. 34 - 66, 2004.

UNIVERSIDADE FEDERAL DO CEARÁ. Laboratório de Solos e Água do Departamento de Ciências do Solo. Classificação dos Solos. Fortaleza: UFC, 1993.

UNIVERSIDADE FEDERAL DO CEARÁ/SEARA DA CIÊNCIA. VI Feira Municipal de Ciências e Cultura. Reaproveitamento da Areia do Formigueiro em Fertilizante para o Solo. SEARA da Ciência: Feiras de Ciências, Fortaleza, out. 2016.

UNIVERSIDADE FEDERAL DO CEARÁ/FACULDADE DE EDUCAÇÃO. VII Seminário Cultura de Paz, Educação e Espiritualidade. Universidade Federal do Ceará: Livro de Resumos, Fortaleza, p. 41, dez. 2016. Disponível em < https://ufcculturadepaz.webnode.com.br/ > Acessado em janeiro de 2020.

VIOLA, Eduardo J. \& LEIS, Héctor R. Meio Ambiente, Desenvolvimento e Cidadania: desafios para as Ciências Socais. São Paulo: Cortez, 1995. 


\section{NOTAS DE AUTOR}

\section{CONTRIBUIÇÃO DE AUTORIA}

Cristiane e Castro Feitosa Melo - Concepção. Coleta de dados, Análise de dados, Elaboração do manuscrito, Participação ativa da discussão dos resultados, Recursos, Software, Visualização, Revisão e aprovação da versão final do trabalho.

\section{FINANCIAMENTO}

Não se aplica.

\section{CONSENTIMENTO DE USO DE IMAGEM}

Não se aplica.

\section{APROVAÇÃO DE COMITÊ DE ÉTICA EM PESQUISA}

Não se aplica.

\section{CONFLITO DE INTERESSES}

Não se aplica.

\section{LICENCCA DE USO}

Este artigo está licenciado sob a Licença Creative Commons CC-BY. Com essa licença você pode compartilhar, adaptar, criar para qualquer fim, desde que atribua a autoria da obra.

\section{HISTÓRICO}

Recebido em: 07-02-2020

Aprovado em: 08-04-2020 